\title{
Gearless Power Transmission Mechanism using 6 Elbow Rods
}

\author{
M. Lokesh ${ }^{1}$, R. Ranjith Kumar ${ }^{1}$, R. Revanth ${ }^{1}$, K. Renugadevi ${ }^{2}$ and S. Ramesh ${ }^{3}$ \\ Student, Department of Mechanical Engineering, R.M.K College of Engineering and Technology, Chennai, India ${ }^{1}$ \\ Assistant Professor, Department of Mechanical Engineering, R.M.K College of Engineering and Technology,India ${ }^{2}$ \\ Assistant General Manager, Tata Motors, Dharwad, India ${ }^{3}$
}

\begin{abstract}
Power transmission with minimum loss is the major criteria while calculating the efficiency of the machine. Most of the machines are using the gear transmission from the input to output but it has the major power loss due to friction. A research in this area brought new ideas to transmit the power using different mechanism. This paper investigates and workouts the new mechanism by replacing the bevel gear with $90^{\circ}$ elbow is used to transmit the power. This transmission system indicates that there is the possibility of right angle power transmission without gears in efficient way. In this paper the power is transmitted with six elbows radially connected at an angle of $60^{\circ}$ with respect to the center of the axis.
\end{abstract}

Keywords: Elbows, Housings, Power transmission, Design stresses.

\section{INTRODUCTION}

Gearless mechanism is a link mechanism of sliding pair, which is also known as El-bow mechanism. The component is exceptionally valuable for cornering or transmitting movements at right points. In automobiles the bevel gears are used widely to get different speed in inner and outer wheels to attain required radius of curvatures to cross the curved areas. This mechanism may be suitable in this type of application and where the power should transmit at the edges of the places. The transmission may be done by setoff elbow rods with input and output housings to get the continuous transmission efficiently. By referring standard design data books, concluded that drives always has very less efficiency. The major factor finding with under frictional forces between the mating gear teeth, the unpredictable chasing of the riggings, the reaction between the teeth can't be overcome and consequently the proficiency can't be more than 55\% of late apparatuses of warm slant sort are being made in poly propylene and epoxy material where the frictional forces are similarly disposed of. Despite the fact that such devices are utilized for moderately little applications the ability is not more than $42 \%$.The El-bow Mechanism transmits the I/P power towards the O/P side such a way that the rakish Forces created in the slacks are essentially transmitted with the assistance of connections which takes up the I/P power and the right point drive is exchanged towards the O/P slack and stick get together. Thus friction less elbow mechanism transmits the power from one end to other end. In this way, it is valued that expertise as high as 90-92\% are believable in a device with gear less transmission component.

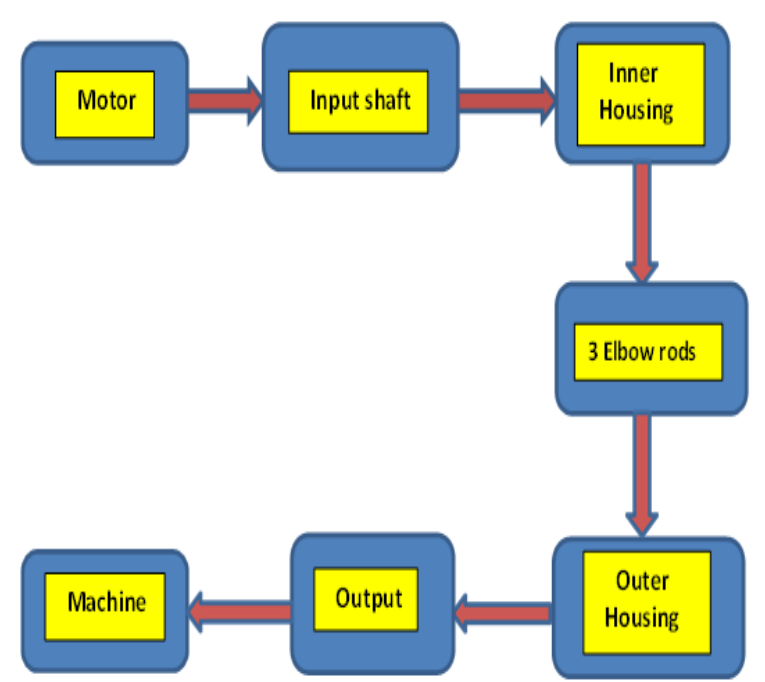

Fig.1. Flowchart Representation of Elbow Transmission 


\section{IARJSET

\section{LITERATURE REVIEW}

AtishLahuPatil et al [1] explained and did the gearless elbow mechanism setup with three elbow rods with obtuse angle of $120^{\circ}$ for transmission of power in the wood cutting machine.

Navneet Bardiya et al [2] calculated and simulated the stresses acting on the mechanism and the reaction forces acting on the points of the joints using analysis software.

Jagushte G. S et al [3] estimated the design stress of the shaft and housing of the transmission setup for proper and smmoth working of the shaft by selecting the desired factor of safety.

R. Somraj et al [4] explained and designed the conceptual multiple views of this transmission systems with three elbow rods.

Amit Kumar and Mukesh Kumar [5] have designed the link mechanism from the input shaft to output shaft to achieve perfect rolling and sliding pair of the mechanism

MahanteshTanodi et al [6] used the oldham's coupling method to transmit the power instead of gears.

\section{EXPERIMENTAL SETUP OF THE TRANSMISSION}

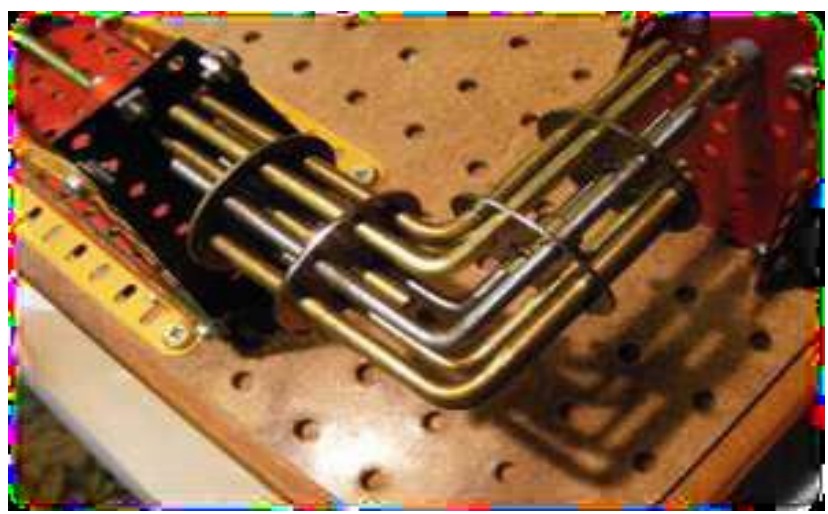

Fig.6. Experimental setup of Elbow Transmission

\section{A. CONSTRUCTION}

An electric motor is used to supply the power at the input end of the shaft. The Input shaft is couple with a cylindrical housing with a depth $8 \mathrm{~cm}$ and it has diameter of $15 \mathrm{~cm}$. Six elbow rods exactly at right angles with an angle of $60^{\circ}$ radially inserted in the input housing at one end of the elbow. The output shaft also connected in the same way at the other end of the outer housing with same parameters (same dimensions as in the inner end)The elbows and housing creates a rolling as well as sliding pair mutually.

\section{B. WORKING}

The Gearless transmission or El-bow mechanism is an apparatus for transmitting power at any desired angle between the driving and driven shaft. The creation of this mechanism would reveal that it contains of a number of links would be between 3 to 8 the more the links the smoother the operation. These links slide inside the housing thus to form a sliding and rolling pair. This mechanism has 3 such sliding pairs. These cylinders are placed in a Hollow pipe and are fastened at $60^{\circ}$ to each other. This experimental setup is mounted on wooden table. Power is supplied by an electric motor.

The operation of the mechanism is explained by the experimental setup given in the fig.6. An unused form of transmission of power on shaft located at an angle. Motion is transmitted from driving to the driven shaft through the rods which are bent to fit in to the $90^{\circ}$ between the shafts. These rods are located at in the holes equally spaced around a circle and they are free to slide in \& out as the shafts revolve. This type of drive is particularly appropriate where quite operation at high speed is vital but only recommended for high duty.

The operation of this transmission will seem by the action of one rod during a single revolution. If the driving shaft is revolving in clockwise the driven shaft will rotate counter clockwise. As input shaft turns through half revolution elbow rods shown in the inner and most effective driving position slides out of both input and output shafts.

The first half revolution and elbow rods then will be at the top then during the remaining half slide in wards until it again reaches to inner most position shown in Fig.6 in the meanwhile the other rods have of sequence distributed through the same cycle of movements all rods are consecutively sliding inwards and outwards. Though this transmission is an old one many mechanics are doubtful about its operation, however it is not only feasible but has proved satisfactory for various applications when the drive is for shafts which are ceaselessly located at given angle. The fig. 6 explains the elbow mechanism with right angle setup, in the same way the setup may be flexible for different 
angle in between any angle $\left(0^{\circ}-90^{\circ}\right)$. It is important to have the holes for a given rod located accurately in the same holes must be equally spaced in radial and circumferential directions, be parallel to each rod should be bent to at angle at which the shaft are to be located. If the holes drilled in the ends of the shafts have "blind" or closed ends, there ought to be a small vent at the bottom of each rod hole for the escape of air compressed by the pumping action of the rods. These holes are useful for oiling to avoid blind holes shafts may have enlarged port or shoulder. This transmission situated centrally and in line with the axis of each shaft and on condition that with a circular groove at each rod or a cross pin to permit rotation of the shaft about the rod simply active as a retaining device for shipping and handling purposed.

As mentioned in first chapter that we are showing two applications of this mechanism at a time.

1) As a wood cutting machine the cutter is attached on the output shaft.

2) The wood cutter is attached at the end of the output shaft, when the power is given to input shaft automatically it transfers to the cutter directly. The speed is adjusted by means of pulley(i.e. rpm). The cutters will also start to rotate along with the shaft the because of cutter is $250 \mathrm{~mm}$.the through slot introduces in the table for free rotation of cutter edges in table. The speed is adjusted by means of pulley (i.e. rpm). The cutters will also start to rotate along with the shaft.

3) air compressor or air pump - the compressor or and pump also introduced in our project when the links inside the drilled holes are reciprocates as well as revolves along the axis of cylinder it gives the compressor effect. Among the six links when first pin goes at inner dead center it sucks the air then it start to move at outer dead center by revolving, it compresses the air against seal and cylinder head disc and does simultaneously by six links and we can get continue discharge of air the quantity.

4) Mechanical seal is defined as a devise which seals by virtue of axial contact pressure between two relatively flat surfaces in a plane right angle to the axis of the shaft. The seal used in EL-BOW $\mathrm{m} / \mathrm{c}$ compressor is stationary type. It is place between cylinder and cylinder head.

\section{POSSIBLE ARRANGEMENTS OF LINKS}

Fig.7 shows a different view of the shaft arrangement which are screwed and angle between them is 90 degrees, which illustrates the connectivity arrangement between the shafts. Fig. 8 shows the front view of the housing along the axis of the transmission.
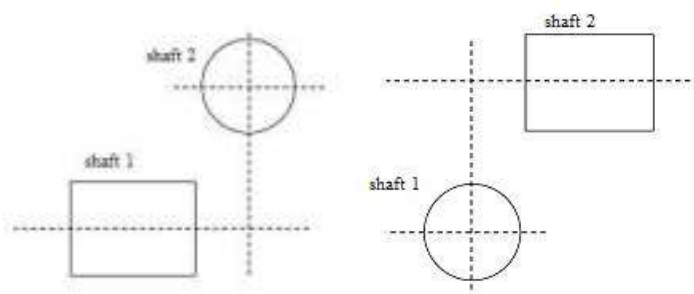

Fig.7. Elbow at $90^{\circ}$ Bend

Different views of the setups are shown in Figure .These views show the arrangement of links and shaft.

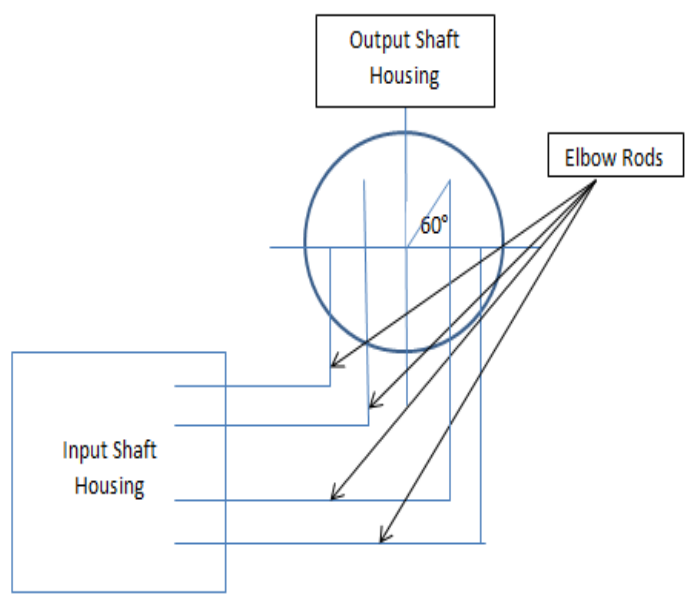

Fig.8. Concept view 


\section{A. Analysis of Mechanism}

From the fig. 7 and fig. 8 shows the various views and setup is clearly established, the front view is used to explain and analyze setup mechanism. Initially the instant shaft 1 starts rotation with 6 links in anticlockwise direction and a reaction force developed at the pin surface which in contact with the shaft and this force transferred to the other end of the pin which is in the shaft and applying on the shaft 2 due to which shaft 2 starts rotating in the same direction as shaft 1 , after 60 degree rotation pin 1 comes at the place of pin $2 \&$ pin 2 comes at the place of pin $3 \&$ pin 3 comes at the place of pin 1 similarly the total 6links replaces the same point periodically by sliding in shaft and self-adjusting. This motion was repeated for every next $60^{\circ}$ and links are swapping the position in successive order as discussed before.

\section{ADVANTAGES}

1. Absence of friction increases the transmission of power from input end to output end.

2. Problems like Backlash, undercutting of teeth are not available in this mechanism.

3. This mechanism may also applicable in parallel offset shaft not only for right angles.

4. Mechanism is very simple to construct and it does not require very high skill labor to construct.

5. The desired speed ratio depends on revolution of shaft and placement angle of the elbow rods.

\section{APPLICATIONS}

This elbow mechanism is already used in very rare cases not in regular some of the applications are listed below

1. The elbow mechanism was first used in the London tower clock in the year 1685

2. This mechanism is also used for a multiple spindle drilling operation simultaneously.

3. It is also used for angular drilling in between 0 to $90^{\circ}$ position.

4. In C.N.C. lathe machines this mechanism is used to lubricate the machine while machining at the end of lubrication pump.

5. In electronic devices and computers this mechanism is used to transmit the power from the device to air blowers.

8. In submarine ships this mechanism is used in periscopes

\section{CONCLUSION}

Elbow transmission mechanism is possible in almost for short lengths and also it is suitable for medium length by increasing the housing diameter. The setup indicates that by increasing the elbow a rod in account increases the smoothness of the transmission. The absence of friction ultimately raises the efficiency of the mechanism. In this paper the mechanism illustrated experimentally and proved with prototype. This mechanism may give the possibility of different angle transmission in between $0^{\circ}-90^{\circ}$ (acute angle) at any point of angle.

\section{REFERENCES}

[1] AtishLahu Patil ${ }^{1}$,Vinay Prabhakar Jadhav ${ }^{2}$, SagarPadmaka Patil ${ }^{3}$, Roshan Suresh Shelar "Gearless Mechanism in Right Angle" International Journal on Recent and Innovation Trends in Computing and Communication ISSN: 2321-8169 Volume: 4 Issue: 4,pp.145 - 149

[2] Navneet Bardiya ${ }^{1}$, karthik. $\mathrm{T}^{2}$, L Bhaskara Rao "Analysis and Simulation of Gearless Transmission Mechanism" International Journal Of Core Engineering \& Management (IJCEM) Volume 1, Issue 6, September 2014

[3] Jagushte G. $S^{1}$ Kudalkar Hrishikesh ${ }^{2}$ Patil Vikas3 Varak Vishal4"Design, Analysis and Fabrication of Gearless Transmission by Elbow Mechanism" International Journal for Scientific Research \& Development| Vol. 4, Issue 02, 2016 | ISSN (online): 2321 -0613

[4] R. Somraj ${ }^{1}$, B. Sailesh "Design and fabrication of gearless power transmission for skew shafts" International Research Journal of Engineering and Technology (IRJET) e-ISSN: 2395 -0056 Volume: 04 Issue: 04 | Apr -2017,ISSN: 2395-0072

[5] Amit Kumar ${ }^{1}$ and Mukesh Kumar "Gearless Power Transmission for Skew Shafts (A SRRS Mechanism)" International Journal of Advanced Science and Technology Vol.79 (2015), pp.61-72 2015.

[6] Mahantesh Tanodi ${ }^{1}$ S. B. Yapalaparvi ${ }^{2}$, Anand. C. Mattikalli ${ }^{3}$, D. N. Inamdar ${ }^{2}$, G. V. Chiniwalar " ${ }^{2}$ Gearless Power Transmission-Offset Parallel Shaft Coupling" International Journal of Engineering Research \& Technology (IJERT) IJERT ISSN: 2278-0181 Vol. 3 Issue 3, March - 2014

[7] A. Kumar and S. Das, "An arrangement for power transmission between co-axial shafts of different diameter", International journal of engineering research and technology.

[8] S. M. S. S. Rattan Tata McGraw Hill Education (India) private limited, New Delhi.

[9] Strength of Materials by R. S. Khurmi\& Gupta.

[10] Design Data Hand Book by Mahadevan.

[11] Machine Design by Bhandari. https://www.youtube.com/watch?v= School of Mechanical and Building Sciences. 